\title{
BIBLIOTECAS PÚBLICAS DO RIO GRANDE DO SUL E O PATRIMÔNIO EDIFICADO: VALOR, NO FUNDO, SIMBÓLICO
}

\author{
Marcia Heloisa Tavares Figueredo Lima \\ Doutora, Professora Adjunta Universidade Federal do Rio Grande do Sul;
} marciahelolima@ufrgs.br

\section{Luciana Prestes Vicente}

Jornalista e Bacharel em Biblioteconomia, Universidade Federal do Rio Grande do Sul; Porto

Alegre, RS.

luprestes@gmail.com

\begin{abstract}
Resumo
Averigua se os bibliotecários ou funcionários responsáveis por bibliotecas públicas estabelecidas em edificações consideradas patrimônios culturais localizadas no Rio Grande do Sul enunciam e demonstram através de práticas a valorização das suas respectivas edificações. Apresenta o conceito de patrimônio cultural com base em bibliografia. Discorre sobre como se dá a atribuição de valor e pontua memória e identidade como elementos constituintes da valoração. Pesquisa a valoração e a divulgação que o patrimônio edificado recebe nas bibliotecas públicas por meio de entrevistas semiestruturadas com três bibliotecárias-chefes e por observações sistemáticas dos seus espaços físicos e dos seus ambientes virtuais. Conclui que a valorização simbólica e a divulgação discursiva do patrimônio edificado são parciais, devido à falta de manutenção material das edificações, o que denota a falta de investimento financeiro do poder público por parte do Governo dos municípios do Estado do Rio Grande do Sul.
\end{abstract}

Palavras-chave: Patrimônio Cultural Edificado. Atribuição de Valor. Memória. Identidade. Bibliotecas Públicas.

\section{PUBLIC LIBRARIES OF RIO GRANDE DO SUL AND THE BUILT CULTURAL HERITAGE: A SYMBOLIC VALUE, IN FACT}

\begin{abstract}
It investigates if the librarians or officials responsible for public libraries established in buildings considered cultural heritage located in Rio Grande do Sul demonstrate, through their practice, the valuation of their respective buildings. It presents the concept of cultural heritage backed by bibliography. It discusses how value is attributed and points to memory and identity as elements that constitute valuation. It researches the valuation and the disclosure that the built patrimony receives in public libraries through semi-structured interviews with three chief librarians and by systematic observations of their physical workplaces and their virtual environments. It concludes that the symbolic valuing and the discursive disclosure of the built patrimony are partial, due to the lack of material maintenance of the buildings, which denotes the lack of financial investment on the part of the local Government of the municipalities of the State of Rio Grande do Sul.
\end{abstract}

Keyword: Built Cultural Heritage. Atttibution of Value. Memory. Identity. Public Libraries. 


\section{INTRODUÇÃO}

As bibliotecas públicas são consideradas centros de memória ao salvaguardar, organizar e disponibilizar a informação presente em seu acervo, contribuindo para a formação educacional e para o desenvolvimento sociocultural das respectivas comunidades às quais servem. Da mesma forma, o patrimônio edificado, impregnado de valores simbólicos, é considerado uma referência de memória e identidade coletiva.

Nessa perspectiva, uma biblioteca pública estabelecida em uma edificação considerada patrimônio cultural está duplamente carregada de informação: acervo e edificação podem ser considerados fontes de conhecimento. Esta dupla informação estabelece uma ponte invisível entre passado, presente e futuro, trazendo consigo memórias e narrativas diversas. Quem fará a leitura dessas informações e quem irá traduzir os dados que estão em pedra, cimento e tinta? O bibliotecário seria responsável pelos desafios de zelar pela preservação e manutenção do patrimônio e de ser um mediador entre patrimônio e usuário? Há realmente uma valorização do patrimônio edificado?

Acrescenta-se também que muitas bibliotecas públicas fazem parte da instauração do centro urbano, sendo parte constituinte da narrativa de uma cidade. Essa característica propiciou que algumas bibliotecas tivessem prédios construídos especificamente para receber uma unidade, outras fossem alocadas em edificações existentes, e outras ainda funcionassem junto a prefeituras ou centros culturais.

Para encontrar respostas às indagações propostas, este artigo tem como objetivo geral averiguar se os bibliotecários ou funcionários responsáveis por bibliotecas públicas estabelecidas em edificações consideradas patrimônio cultural no Rio Grande do Sul promovem objetivamente uma valorização subjetiva, mas enunciada, da edificação. O objetivo específico primeiro foi mapear as bibliotecas públicas estabelecidas em edificações consideradas patrimônios culturais no Estado. Diante do resultado, selecionaram-se três unidades para dar seguimento à proposta do trabalho. O segundo objetivo específico envolveu analisar a relação entre a equipe (especificamente do bibliotecário) com uma imaginada valorização do patrimônio. O terceiro foi apurar se são promovidas ações discursivo-materiais de valorização do patrimônio edificado da unidade por meio das enunciações presentes em materiais impressos de divulgação (folhetos, flyers ou catálogos), nos ambientes virtuais (site oficial, blogs e redes sociais), e por meio das atividades culturais. O quarto objetivo específico pretendeu verificar se há orçamento destinado à manutenção da edificação. 
O mapeamento proposto se mostrou relevante, pois, ao buscar informações junto ao Sistema Estadual de Bibliotecas Públicas do Rio Grande do Sul (SEBP/RS) sobre as unidades estabelecidas em edificações consideradas patrimônios culturais no Estado, o órgão informou que não possuía esse controle. A mesma resposta foi obtida ao consultar o Conselho Regional de Biblioteconomia da 10 Região (CRB10).

\section{METODOLOGIA}

O tipo de pesquisa que se mostrou mais adequado para elucidar os objetivos propostos foi a abordagem qualitativa, por oferecer uma interpretação dos dados coletados e permitir atribuição de significados. Segundo Gerhardt e Silveira (2009), essa abordagem preocupa-se com aspectos da realidade que não podem ser quantificados, centrando-se na compreensão e explicação da dinâmica das relações sociais. Ao averiguar se os bibliotecários valorizam o fato de sua unidade funcionar em uma edificação considerada patrimônio cultural, não houve preocupação com representatividade numérica, mas sim com o aprofundamento da compreensão do pressuposto.

Com o objetivo de proporcionar familiaridade com o tema proposto e com vistas a torná-lo mais explícito, a pesquisa enquadra-se naquilo que Gil (2002) descreveu como pesquisa exploratória, pois não foram encontrados estudos anteriores que trouxessem essa abordagem mencionada no objetivo geral; tampouco foram localizadas pesquisas que contivessem esse mapeamento sobre as bibliotecas públicas no Rio Grande do Sul que estão estabelecidas em edificações consideradas patrimônio cultural.

O autor ainda completa que, na maioria dos casos, a pesquisa exploratória assume a forma de pesquisa bibliográfica ou de estudo de caso. Neste artigo foram usadas a pesquisa bibliográfica (com um apanhado de referências teóricas e publicadas), a pesquisa documental (realizada por meio de documentos contemporâneos ou retrospectivos), a pesquisa eletrônica (constituída por informações extraídas de endereços eletrônicos), e as entrevistas semiestruturadas com profissionais que possuem experiência com o problema pesquisado.

os procedimentos técnicos utilizados, a escolha foi por um estudo de caso. Fonseca (2002, p. 33) afirma como o estudo de caso "pode ser caracterizado como um estudo de uma entidade bem definida, como um programa, uma instituição, um sistema educativo, uma pessoa, ou uma unidade social e Gil (2002) acrescenta que seu propósito é possibilitar uma 
visão global do problema ou de identificar possíveis fatores que o influenciam ou são por ele influenciados.

O universo da pesquisa constitui-se das bibliotecas públicas estabelecidas em edificações consideradas patrimônio cultural no Rio Grande do Sul, conjunto a partir do qual escolheram-se três unidades para análise. $\mathrm{O}$ estudo de caso requer a utilização de múltiplas técnicas de coleta de dados para garantir a profundidade necessária, de forma a conferir maior credibilidade aos resultados e a inserção do caso no seu contexto. Requer a utilização de fontes documentais, entrevistas e observações, todas as três técnicas de coleta utilizadas.

As entrevistas semiestruturadas foram realizadas com os bibliotecários das bibliotecas públicas escolhidas para ouvir suas enunciações sobre a valorização do patrimônio cultural onde a unidade está estabelecida. As perguntas contemplaram o objetivo principal e os objetivos específicos, que pretenderam identificar se bibliotecários promovem ações de valorização da edificação da unidade por meio das enunciações presentes em materiais de divulgação (discurso escrito) e por meio das atividades promovidas (práticas).

A observação foi utilizada para complementar as informações recolhidas nas entrevistas, verificando como se dá a divulgação da edificação enquanto patrimônio cultural nos espaços físicos e nos ambientes virtuais das bibliotecas escolhidas. Foi verificado o uso do site oficial das mesmas, seus blogs, a rede social Twitter e a rede social Facebook (as duas redes sociais mais populares atualmente), que foram recuperadas por meio do buscador Google. Essa observação foi também sistemática (com instrumento de coleta de dados), nãoparticipante e individual. Durante o período de seis meses, de março a novembro de 2017, verificou-se diariamente a existência de qualquer menção ao patrimônio cultural nos perfis das redes sociais escolhidas e também no site oficial e blogs das instituições, por meio de um roteiro para a observação.

O mapeamento e a escolha das bibliotecas públicas foi realizada por meio das unidades cadastradas no SEBP/RS ${ }^{1}$. No primeiro momento foram enviadas correspondências para as 534 bibliotecas públicas cadastradas ao sistema, com o esclarecimento da realização do trabalho final do curso de Biblioteconomia da UFRGS e com a questão "Sua biblioteca funciona em uma edificação considerada patrimônio cultural?" seguida do esclarecimento sobre o que é

\footnotetext{
${ }^{1}$ A lista se encontra disponível no blog do Sistema Estadual de Bibliotecas Públicas do Rio Grande do Sul e pode ser acessada no seguinte link: <http://sebprs.blogspot.com.br/p/lista-de-bibliotecas-dors.html>. Acesso em: 21 set. 2017.
} 
patrimônio cultural com a referência do que a Constituição Brasileira define. Foram obtidas 144 respostas, sendo que 27 responderam afirmativamente.

Para abordar a temática da pesquisa, as próximas seções tratam de assuntos pertinentes, como o caráter amplo do conceito de patrimônio e a atribuição de valor. Também traz reflexões sobre memória e identidade.

\section{PATRIMÔNIO CULTURAL}

Muitos são os significados suscitados pela expressão "patrimônio cultural". A expressão chegou ao final dos primeiros vinte anos do século XXI reavaliada e ampliada. Pensada somente como forma de preservação de uma herança material, seu domínio se ampliou com mais uma especificação, patrimônio imaterial, no ano 2000. Essa ampliação decorreu do seu estreito relacionamento com outros conceitos - como antiguidade, coleção, história, preservação, identidade cultural e memória coletiva -, além da permeabilidade com outros campos, como Antropologia, História, Arquitetura e Artes Visuais. A palavra "patrimônio" saiu do âmbito privado e familiar para o coletivo como resultado de transformações sociais, políticas e econômicas que se desenrolaram no mundo, começando na França, como consequência da Revolução Francesa. No Brasil, na década de 1930, a ampliação da concepção de patrimônio e o seu caráter institucional e legal deram seus primeiros passos, chegando hoje à denominação de patrimônio cultural, segundo Gonçalves (2007), desempenhando uma função social e simbólica de mediação entre o passado, o presente e o futuro de um grupo, assegurando a sua continuidade. $\mathrm{O}$ autor acrescenta que é nesse processo de reclassificação que é assegurado aos objetos sua continuidade no tempo e no espaço.

Também na França, a palavra "patrimônio", acrescida do adjetivo "cultural”, começou a ser usada em 1959 por André Malraux, então ministro de Estado da Cultura. Patrimônio cultural passou a abranger monumento e monumento histórico, além de todas as outras formas que a palavra pode estar combinada, como patrimônio artístico, patrimônio histórico e patrimônio edificado. A historiadora francesa Françoise Choay (2006) destaca que esse uso passou a se replicar em outros países da Europa, ainda mais quando o Conselho da Europa multiplicou recomendações, declarações, cartas e resoluções a serviço do "patrimônio europeu" (CHOAY, 2006, p. 28).

De acordo com Gonçalves (2007), o conceito de patrimônio cultural reúne saberes e valores que podem estar representados em conjuntos de objetos materiais classificados. Esses 
objetos estariam a "inventar" a trajetória de uma população, uma vez que materializam uma teia de categorias de pensamentos por meio dos quais se estabelece o sentimento de pertencimento, individual e coletivamente. A categoria "patrimônio cultural" assumiria, então, uma dimensão universal, não sendo um fenômeno ocidental e moderno, mas sim se manifestando de forma diversa em toda e qualquer sociedade. Gonçalves (2007) complementa ainda que a legitimidade da definição de patrimônio cultural, identidade e memória oscila como interpretação, apropriação e recondução discursiva no embate entre os grupos étnicos e coletividades dominantes e estamentos inferiores.

Da mesma forma, Poulot (2008) diz que patrimônio é um conjunto de saberes, valores e regimes de sentido elaborados ao longo de processos de formação de identidades coletivas, das comunidades - particularmente as nacionais -, independente de quem começou o processo ou ação de reconhecimento. Para ele, a noção de patrimônio envolve um conjunto de posses que cumpre identificar como transmissíveis em um grupo humano ou uma sociedade, capaz ou suscetível de reconhecê-las como suas, de demonstrar a sua coerência e de organizar a sua recepção. Além disso, acrescenta que é necessário um conjunto de valores políticos que favoreça uma articulação dos legados do passado para permitir a continuidade da valoração de algo como patrimônio.

O patrimônio edificado, também chamado de patrimônio cultural edificado ou bem material edificado, está contido neste conjunto maior chamado patrimônio cultural. É visto como um documento cujas evidências materiais autênticas de sua trajetória devem ser respeitadas, por estar impregnado de uma representação simbólica e tornando visível o passado de maneira concreta, com significados e possibilidades de leitura relacionadas a tempos e lugares. Ofereceria ainda a chance de questionar o passado, de estabelecer novas conexões e revisitá-lo por diferentes perspectivas. Ricoeur (2007) expressa que a glória da arquitetura é "[...] tornar presente não aquilo que não é mais, mas aquilo que foi, através do que não é mais.". Patrimônio edificado seria uma re-significação às edificações remanescentes não mais utilizadas em suas funções originais, transportando o pretérito até o presente.

Machado (2008) relata que no Brasil não se constituiu uma cultura sólida de participação da sociedade civil na preservação do patrimônio cultural. Há, no entanto, algumas referências de comunidades envolvidas na preservação de patrimônios, sobretudo religiosos, e nos cuidados na proteção de acervos sacros em relação a roubo e dilapidação. Os processos que envolvem a participação e adesão da sociedade, para Machado (2008, p. 284), passam necessariamente pela educação patrimonial formal ou informal. 
Para o autor, os setores públicos e privados são co-responsáveis por sua integridade e autenticidade, devendo cooperativamente viabilizar os meios e compartilhar experiências para adoção de soluções bem orientadas e para evitar a dispersão ou a duplicação de esforços. Esse seria um dos motivos pelos quais todos os países hoje buscam envolver a sociedade nas responsabilidades da preservação patrimonial e se dedicam ao desenvolvimento de programas educacionais sistemáticos nessa área.

A atribuição de valor a um objeto simbólico para um grupo é o começo de uma caminhada e de um processo de proteção legitimada que poderá levá-lo à condição de patrimônio cultural no âmbito regional, nacional ou internacional. $O$ processo de patrimonialização pode ser visto como uma forma de assentamento dessa valoração, sendo o que veremos a seguir.

\section{ATRIBUIÇÃO DE VALOR SIMBÓLICO}

Quando um objeto - prédios, obras de arte, monumentos, lugares históricos, relíquias, documentos -, ganha a denominação de patrimônio cultural, é porque lhe foi atribuído algum valor sentimental, memorial, histórico, artístico ou social. Pode-se afirmar que o patrimônio cultural de uma região, nação ou da humanidade tem uma existência resultante de uma série de escolhas e seleções que estão vinculadas a valores.

A noção de patrimônio cultural, na Europa foi fomentada e constituída no bojo da formação dos Estados Nacionais: as representações e referências para relembrar um passado comum tornaram-se fundamentais na busca de formar o sentimento de "Nação": "somos na medida em que nos lembramos." (GONÇALVES, 2007, p. 151). O passado precisou ser materializado para ser revisitado quantas vezes fossem necessárias para construir memórias, tradições e identidades para a coletividade. Moedas, medalhas, objetos, prédios e até ruínas ganharam valor monumental: testemunhavam pelo que traziam de factual e de conteúdo histórico.

Para Costa (2008), o fenômeno da patrimonialização, ou da atribuição de valor a um determinado bem cultural com a intenção de que este faça parte da categoria patrimônio cultural, na sociedade capitalista será visto pela seguinte prisma: “Aquilo que é recebido como herança e que se apresenta como símbolo de poder social, econômico e político." (COSTA, 2008, p. 121). Nessa perspectiva de valoração, Bourdieu (1989) cunhou a expressão "capital cultural" para analisar os grupos, tendo como referência os recursos econômicos. Além do 
capital cultural existiriam outras formas de capital: o capital econômico, o social (os contatos) e o capital simbólico (o prestígio), que juntos formam as classes sociais ou o espaço multidimensional das formas de poder.

Pela concepção de Bourdieu (1989), os grupos sociais negociam significados e enfrentam disputas simbólicas por distinção e por legitimidade. O que será legitimado será resultado das produções simbólicas que servem como instrumento de dominação por parte de quem detém o capital e o poder. Essa legitimidade oficial é uma imposição simbólica que tem a seu favor toda a força do coletivo, do consenso, do senso comum, por ser operado por um mandatário do Estado (BOURDIEU, 1989).

Pode-se entender pela perspectiva de Bourdieu (1989) que a legitimação patrimonial por designação, ou seja, por um processo pelo qual o patrimônio ganha um rótulo honorífico, é resultado de uma valoração simbólica referendada por especialistas. Seria a consequência de uma relação e estratégia de cima para baixo, com pouco espaço para contribuições do público em geral, resultando em designações elitistas e sem espaço para o controverso.

Sobre poder e domínio, Choay (2006) afirma que um presidente de câmara, um inspetor dos monumentos históricos, um arquiteto, um urbanista ou um administrador do patrimônio são figuras capazes de mudar o destino de um monumento ou de uma cidade antiga, em decorrência do poder a eles instituído. Argumenta ainda, assim como Costa (2008) e Bourdieu (1989), que a valorização remete à noção de mais-valia: "Mais-valia de interesse, de agrado, de beleza, mas também a de atrair, cujas conotações econômicas não é preciso salientar." (CHOAY, 2006, p. 212). Choay (2006) reitera que a valorização do patrimônio apresenta formas múltiplas, contornos imprecisos, que muitas vezes se confundem ou se associam. Aponta que conservação e restauro são alguns dos pontos fundamentais de qualquer valorização dentre as múltiplas operações destinadas a enaltecer o monumento histórico e a transformá-lo, eventualmente, em produto econômico. Para a historiadora francesa, o campo patrimonial no mundo inteiro é um palco de um combate desigual e duvidoso, no qual, todavia, o poder dos indivíduos continua grande.

A abordagem baseada em valor inclui um conjunto mais amplo envolvendo não apenas um pequeno grupo de especialistas em patrimônio, mas uma variedade de interessados $\mathrm{Na}$ próxima seção, a intenção é detalhar reflexões sobre memória e identidade, os primeiros atributos conferidas a um objeto com valor documental e simbólico. 


\subsection{Memória e Identidade}

Para Pesavento (2008), em uma cidade as pessoas possuem pontos de ancoragem da memória. Seriam lugares onde viveram-se experiências do cotidiano ou situações excepcionais. Esses espaços seriam dotados de significados e capazes de fazer de cada cidade um espaço urbano qualificado. Mais do que espaços, meras extensões da superfície, tratam-se de territórios, porque possuem carga simbólica que lhes dá identidade. Apropriados pelo social, esse territórios "são lugares de memória, como aponta Pierre Nora (1993/1997), ou ainda espaços que contém um tempo, como assinala Paul Ricoeur (1998)." (PESAVENTO, 2008, p. $3)$.

A historiadora reflete que há pontos de ancoragem individuais, que remetem a vivências particulares; mas há outros pontos coletivos, resultado, muitas vezes, da indução e da educação que os identifica como lugares da cidade carregados de informações e memórias comuns a todos, resultando em um processo de vivência do imaginário urbano coletivo. Pesavento (2008) afirma ainda que os lugares de memória de uma cidade são também lugares de história, pois História e memória são ambas narrativas do passado que presentificam uma ausência, reconfigurando uma atemporalidade escoada. Mesmo Nora (1993) reconhece que os "lugares de memória" são híbridos de memória e história: uma sentimento vivido, a outra, atribuída profissional e intelectualmente.

Halbwachs (2006) complementa essa ideia ao refletir que um dos objetivos da História talvez seja justamente o de lançar uma ponte entre passado e presente e restabelecer essa continuidade interrompida, especialmente quando se tem a sorte de encontrar memórias inéditas. Para o sociólogo francês, o passado deixou na sociedade muitos vestígios - às vezes visíveis, como em edificações ou lugares -, chamados de ilhotas do passado conservadas com eram, e tão bem conservadas que são capazes de transportar as pessoas para cinquenta ou sessenta anos atrás. Além disso, os costumes modernos repousam sobre camadas antigas que afloram em mais de um lugar.

O grande precursor do conceito de lugares de memória foi o historiador francês Pierre Nora. Convencido de que os países e os grupos sociais de sua atualidade sofriam evidente transformação na relação que mantinham tradicionalmente com o passado, Nora (1993) atribui este fato a uma das questões significativas da cultura contemporânea: um sentimento de perda do passado e a necessidade de lhe consagrar lugares de rememoração. Nora (1993) estabeleceu distinções entre os lugares de memória, destacando que estes podem ser materiais, simbólicos 
e funcionais: um lugar material pode ser uma biblioteca, um arquivo ou um museu, que só são lugares de memória se receberem valor simbólico através da imaginação; um lugar funcional pode ser encontrado em um livro, testamento ou manual, que somente serão lugares de memória se forem investidos de um ritual de consagração; ou, enfim, um lugar simbólico pode ser um gesto em uma fração do tempo, como um minuto de silêncio, que constitui uma lembrança concentrada.

Para Araripe (2004) é mister que se veja o patrimônio cultural,como parte integrante da comunidade onde está inserido, como memória social, propondo "sua utilização como fonte de informação [...] coadjuvante na promoção de tudo o que possibilita ao sujeito o crescimento pessoal e coletivo [...]"(ARARIPE, 2004, p. 113). A pesquisadora lembra que, quando se criou Instituto do Patrimônio Histórico e Artístico Nacional (Iphan), as discussões sobre patrimônio cultural eram determinadas por arquitetos e alguns poucos técnicos da cultura, o que mostrava que os bens patrimoniais instituídos estavam relacionados a patrimônios edificados - prédios e monumentos. Atualmente, para Araripe (2004), falar de patrimônio cultural estabelece a relação com o conjunto de tudo que tem significação ou sentido social materializado (visível) ou manifestações da cultura que se apresentam através do cidadão comum.

Segundo Araripe (2004), para manter a memória social como fonte para reflexão histórica na construção do espaço urbano, seria interessante analisar a necessidade e a possibilidade de uso social desse patrimônio em um processo educacional. O patrimônio ganharia uma função pedagógica. Argumenta que a utilidade social do que se apresenta como patrimônio é fundamental para sua percepção e manutenção.

A memória contida no patrimônio permite formação de identidade e laços de pertencimento com a comunidade onde se insere. Para ela, "deve existir uma relação de reconhecimento e pertencimento - de identidade - daquilo que se constitui como patrimônio com a história de seu povo e suas práticas cotidianas." (ARARIPE, 2004, p. 114).

No entanto, a identidade é um valor subjetivo, como a maioria dos valores patrimoniais instituídos. A conexão com o passado e as origens sociais reverbera de forma original em cada indivíduo. Para Yañes (2006), no presente, as novas tendências patrimoniais tendem a instrumentalizar a identidade para que ela sirva como referência não só de um passado mais ou menos remoto, mas do presente também. Para ela, seria importante que as pessoas tivessem consciência da necessidade de preservar um patrimônio como forma de preservar a realidade da qual fazem partes. 
De acordo com Halbwachs (2006), identidades fundamentam-se em dados reais e objetivos, recolhendo traços, hábitos, maneiras de ser e acontecimentos do passado, tal como lugares e momentos. A identidade se mostra e se exibe em ritos e práticas sociais e se daria a ver - como no caso dos monumentos, feitos para lembrar. E tais marcos têm seu local preferencial de referência nos centros urbanos. A paisagem, carregada do simbólico, constituída de espaços, atores, práticas deve ser reconstruída em operações mentais de produção de sentido: "nós 'veremos' para além daquilo que é visto. Por uma operação mental, reconstituímos. " (HALBWACHS, 2006, p. 7).

Gonçalves (2007) complementa a ideia de Halbwachs (2006) estabelecendo um paralelo entre identidade individual e memória familiar formada pelo conjunto de objetos "herdados" que permanecem por gerações e identidade da Nação, definida por seus monumentos - aquele conjunto de bens culturais associados ao passado nacional. Para Gonçalves (2007), o patrimônio tem a capacidade de evocar visual e sensivelmente ideias e valores do passado pela associação entre espaços e objetos.

Le Goff (1982) argumenta que a memória coletiva é um dos elementos mais importantes das sociedades em desenvolvimento, das classes dominantes e das classes dominadas, lutando todas pelo poder ou pela vida, por sobreviver e por progredir.

Após uma série de referências teóricas apresentadas para dar conta do conceito de patrimônio e da atribuição de valor dada a uma edificação, na próxima seção os resultados obtidos por meio da metodologia aplicada para dar conta dos objetivos propostos.

\section{RESULTADOS}

Foram enviadas correspondências eletrônicas para as 534 bibliotecas públicas cadastradas no Sistema Estadual de Bibliotecas Públicas do Rio Grande do Sul, indagando se a unidade estava estabelecida em uma edificação considerada patrimônio cultural. Somente 134 responderam - afirmativa ou negativamente - à correspondência eletrônica enviada. Oitenta mensagens voltaram notificando que o endereço eletrônico estava errado, o que levou a um novo contato com SEBP/RS, mas o sistema informou que os dados eram fornecidos pelas unidades, de forma que estavam atualizados, mas que poderia ter algum erro de informação. Dentro desse conjunto, além das correspondências que voltaram por endereços errados, também houve as bibliotecas que não responderam. Para estas foram remetidas novas correspondências, em uma segunda tentativa de obter um maior número de respostas. Mesmo 
assim o número das correspondências não respondidas ficou em 363. Das 144 respostas recebidas, 27 afirmaram que estão estabelecidas em edificações consideradas patrimônio cultural.

Procurou-se averiguar no Google, a existência de ambientes virtuais das bibliotecas que não responderam ou cujas correspondências retornaram, com o intuito de verificar se havia informação registrada sobre a edificação. O resultado não foi satisfatório, pois a grande maioria não possui site, blog ou Facebook, e nos sites das Prefeituras, na maioria, não constam informações sobre as respectivas bibliotecas municipais. A última tentativa foi o Google Maps, para verificar o endereço fornecido pelo SEBP/RS, o que também se tornou inviável, pela falta total de identificação no mapa de muitos lugares das cidades da lista do Sistema. Uma primeira barreira para a pesquisa foi a dificuldade de contato com essas instituições, o que não deveria ocorrer, já que são instituições que devem prestar atendimento à população. Vários e-mails fornecidos pelas prefeituras ou pelas próprias bibliotecas não funcionam, ou estão em manutenção, inviabilizando uma correspondência virtual.

O primeiro resultado original desta pesquisa é apresentado a seguir em um quadro, em forma de lista e ordem alfabética pelo nome da cidade sede das 27 bibliotecas gaúchas localizadas em prédios históricos ou consideradas patrimônio cultural pela comunidade. Algumas das edificações não estão tombadas, mas o reconhecimento do valor histórico costuma ser anterior ao tombamento, como explicitado na parte teórica. Há bibliotecas com prédio próprio e várias que dividem espaço com outras instituições culturais. 
Quadro 1 - Mapeamento de Bibliotecas Públicas por Cidades

\begin{tabular}{|c|c|c|}
\hline Cidade & Biblioteca Pública & Características do patrimônio edificado \\
\hline Agudo & Bib. Pub. Mun. Aldo Berger & $\begin{array}{l}\text { O prédio apresenta-se com referências à arquitetura } \\
\text { pomerana, com telhado de grande inclinação. Essa } \\
\text { arquitetura é resultado da imigração alemã, muitos } \\
\text { provenientes da Pomerânia, com chegada na região } \\
\text { em 1857. Edificação antiga onde era estabelecida a } \\
\text { Secretaria de Educação do Município. }\end{array}$ \\
\hline Antônio Prado & Bib. Pub. Mun. Hildo da Costa Guillox & $\begin{array}{l}\text { Edificação construída em alvenaria entre } 1896 \text { e } \\
1900 \text { para ser a casa do comerciante Vittorio } \\
\text { Faccioli, mas nunca foi usada como residência. No } \\
\text { local foi realizada a primeira eleição em Antônio } \\
\text { Prado. Em 1921, o município adquiriu a } \\
\text { propriedade por } 40 \text { contos de réis. Em } 1986 \text {, o } \\
\text { edifício foi bastante reformado e ampliado nos } \\
\text { fundos, e passou a abrigar também a Câmara de } \\
\text { Vereadores, que permaneceu na casa até } 2008 \text {. O } \\
\text { prédio é tombado pelo município como patrimônio } \\
\text { cultural. }\end{array}$ \\
\hline Caçapava do Sul & Bib. Pub. Mun. Domingos José de Almeida & $\begin{array}{l}\text { Edificação de } 1787 \text { é conhecida por Reduto } \\
\text { Farroupilha. Abrigou os revoltosos e nela já } \\
\text { funcionou a Câmara de Vereadores, uma cadeia, } \\
\text { uma escola pública e o Fórum. Atualmente, o } \\
\text { imóvel abriga o Museu Municipal Lanceiros } \\
\text { Negros, a Biblioteca Pública Municipal Domingos } \\
\text { José de Almeida e o Arquivo Histórico da cidade. } \\
\text { Este ano, 2017, o imóvel passou por obras para } \\
\text { restauro. }\end{array}$ \\
\hline Cachoeira do Sul & $\begin{array}{l}\text { Bib. Pub. Mun. Doutor João Minssen } \\
\text { Fundada em } 1946 \text { por João Minssen, seu } \\
\text { primeiro diretor e depois patrono. }\end{array}$ & $\begin{array}{l}\text { Desde 1998, a biblioteca está instalada na Casa de } \\
\text { Cultura Paulo Salzano Vieira da Cunha, considerada } \\
\text { patrimônio cultural. Tem como documento de sua } \\
\text { origem a correspondência de } 5 \text { de maio de } 1880 \text {, } \\
\text { com a primeira iniciativa de criar em Cachoeira uma } \\
\text { biblioteca pública. }\end{array}$ \\
\hline Canoas & $\begin{array}{l}\text { Bib. Pub. Mun. João Palma da Silva } \\
\text { Fundada em } 1959 \text { e inaugurada em } 1966\end{array}$ & $\begin{array}{l}\text { Após algumas mudanças de local, a Biblioteca } \\
\text { Pública João Palma da Silva constituiu sede no } \\
\text { antigo prédio do Fórum, no centro de Canoas. O } \\
\text { nome oficial João Palma da Silva foi adotado a } \\
\text { partir }\end{array}$ \\
\hline $\begin{array}{l}\text { Campestre da } \\
\text { Serra }\end{array}$ & Bib. Pub. Mun. Fabrícia Rech Cechinato & $\begin{array}{l}\text { A resposta foi positiva para a pergunta "Está em um } \\
\text { prédio de valor cultural e histórico para o } \\
\text { município?". No entanto não foi conseguido mais } \\
\text { informações sobre a edificação. }\end{array}$ \\
\hline Caxias do Sul & $\begin{array}{l}\text { Bib. Pub. Mun. Parque Largo da Estação } \\
\text { Especializada em literatura infantojuvenil }\end{array}$ & $\begin{array}{l}\text { Edificação histórica abrigava as oficinas das } \\
\text { locomotivas da Estação Férrea de Caxias do Sul. O } \\
\text { espaço foi restaurado e inaugurado em abril de } \\
2013 \text {, oferecendo opções para a comunidade na área } \\
\text { do livro, leitura e literatura. Faz parte direta na } \\
\text { ampliação do uso do complexo cultural do Largo da } \\
\text { Estação. Está entre as atrações turísticas da cidade. } \\
\text { Foi tombado pelo IPHAE }\end{array}$ \\
\hline Farroupilha & $\begin{array}{l}\text { Bib. Pub. Mun. Olavo Bilac } \\
\text { Criada em } 1940\end{array}$ & $\begin{array}{l}\text { Edificação considerada patrimônio cultural, com } \\
\text { previsão de restauro. Em } 2010 \text {, a edificação passou } \\
\text { a ser patrimônio cultural do município. }\end{array}$ \\
\hline Gramado & Bib. Pub. Mun. Cyro Martins & $\begin{array}{l}\text { A Biblioteca funciona em uma casa considerada } \\
\text { patrimônio cultural. }\end{array}$ \\
\hline Horizontina & Bib. Pub. Mun. Edmar Albino Sulzbach & $\begin{array}{l}\mathrm{O} \text { prédio é um antigo Moinho, considerado } \\
\text { referência em termos de cultura e história do } \\
\text { município. }\end{array}$ \\
\hline Mormaço & Bib. Pub. Mun. sem nome & $\begin{array}{l}\text { A biblioteca funciona juntamente ao prédio da } \\
\text { Secretaria Municipal de Educação, Cultura e } \\
\text { Desporto, sendo de valor cultural. }\end{array}$ \\
\hline Nova Pádua & Bib. Pub. Mun. Flávio Luiz Ferrarini & $\begin{array}{l}\text { A biblioteca está instalada em um prédio público } \\
\text { histórico, sendo o mais antigo do município. }\end{array}$ \\
\hline
\end{tabular}




\begin{tabular}{|c|c|c|}
\hline Novo Hamburgo & $\begin{array}{l}\text { Bib. Pub. Mun. Machado de Assis } \\
\text { Fundada em 1946, com abertura em } 1953 .\end{array}$ & $\begin{array}{l}\text { Edificação de } 1908 \text { abrigou uma escola entre } 1909 \\
\text { e } 1921 \text {. Em 1978, foi tombada como patrimônio } \\
\text { cultural e, em 1982, foi entregue à população como } \\
\text { sede da biblioteca. }\end{array}$ \\
\hline Osório & Bib. Pub. Mun. Fernandes Bastos & $\begin{array}{l}\text { Edificação é do final do século XIX e passou por } \\
\text { reformas internas, porém não é tombada. É } \\
\text { considerado prédio de valor cultural por se tratar de } \\
\text { uma das primeiras construções da cidade. }\end{array}$ \\
\hline Pelotas & $\begin{array}{l}\text { Bibliotheca Pública Pelotense } \\
\text { Fundada em } 1875 \text { por diversos cavalheiros da } \\
\text { comunidade }\end{array}$ & $\begin{array}{l}\text { Edificação construída de } 1878 \text { a } 1881 \text {. João Simões } \\
\text { Lopes inaugurou os alicerces do prédio projetado } \\
\text { por José Izella. De } 1811 \text { a } 1813 \text {, Caetano Casaretto } \\
\text { projetou o segundo piso. O arco da entrada feito de } \\
\text { granito veio de Portugal. Erguido em etapas entre os } \\
\text { anos de } 1881 \text { e } 1915 \text {, o primeiro piso, projeto do } \\
\text { arquiteto italiano José Izella, foi inaugurado em } \\
\text { 1888. Caetano Casaretto projetou o segundo piso, } \\
\text { que foi construído a partir do ano de } 1911 \text {. Possui a } \\
\text { fachada em estilo neoclássico, contornada com } \\
\text { bustos do calendário positivista (circundando o } \\
\text { prédio), enquanto que a Sala de Leitura possui estilo } \\
\text { Império e as outras salas e salões mesclam-se em } \\
\text { estilo rococó, egípcio, gótico e florentino. Em } 1986 \\
\text { o prédio da Biblioteca foi tombado pelo IPHAE e, } \\
\text { em } 2000, \text { pelo Iphan. }\end{array}$ \\
\hline Porto Alegre & $\begin{array}{l}\text { Biblioteca Pública do Estado do Rio Grande } \\
\text { do Sul } \\
\text { Em } 1871 \text {, foi feito o pedido para sua criação. } \\
\text { Em } 21 \text { de janeiro de } 1877 \text {, a BPE/RS foi aberta } \\
\text { ao público. }\end{array}$ & $\begin{array}{l}\text { Em 1915, foi transferida para a sede atual na rua } \\
\text { Riachuelo. Na sua fachada, como em seu interior, } \\
\text { apresenta influência da doutrina positivista, com } \\
\text { estilo neoclássico, contornada com bustos do } \\
\text { calendário positivista. A porta principal do vestíbulo } \\
\text { é em madeira esculpida e emoldurada em gesso } \\
\text { dourado com soleira em mármore. Em estilo } \\
\text { Império, a Sala de Leitura preserva a pintura } \\
\text { original das paredes, hoje recoberta com tinta PVA } \\
\text { cinza. Nas outras salas e salões diversificam-se os } \\
\text { estilos, entre eles rococó, egípcio, gótico e } \\
\text { florentino }\end{array}$ \\
\hline Porto Alegre & $\begin{array}{l}\text { Bib. Pub. Mun. Josué Guimarães } \\
\text { Fundada em } 1928\end{array}$ & $\begin{array}{l}\text { Edificação é um centro cultural, sendo considerado } \\
\text { patrimônio cultural. A biblioteca passou por outros } \\
\text { lugares até se estabelecer de modo definitivo, em } \\
\text { 1978, com a inauguração do Centro Municipal de } \\
\text { Cultura Arte e Lazer Lupicínio Rodrigues. }\end{array}$ \\
\hline Porto Alegre & $\begin{array}{l}\text { Bib. Pub. Mun. Lucília Minssen } \\
\text { Fundada em 1954, para oferecer um acervo de } \\
\text { livros infanto-juvenis e promover atividades } \\
\text { culturais voltadas para crianças e jovens }\end{array}$ & $\begin{array}{l}\text { Unidade está estabelecida no quinto andar da Casa } \\
\text { de Cultura Mario Quintana (CCMQ), edificação de } \\
\text { 1918, construída pelo arquiteto alemão Theodor } \\
\text { Alexander Josef Wiederspahn, onde funcionou o } \\
\text { Hotel Majestic. Em } 29 \text { de dezembro de } 1982 \text { o } \\
\text { governo do Estado adquiriu o imóvel, e, um ano } \\
\text { mais tarde, foi arrolada como patrimônio cultural, } \\
\text { tendo início, a partir de então, sua transformação em } \\
\text { centro cultural. }\end{array}$ \\
\hline Porto Alegre & $\begin{array}{l}\text { Bib. Pub. Mun. Erico Veríssimo } \\
\text { Fundada em 1990, sendo especializada em } \\
\text { Literatura e Artes. }\end{array}$ & Também funciona na CCMQ \\
\hline Quatro Irmãos & Biblioteca Pública Municipal & $\begin{array}{l}\text { A Biblioteca funciona em uma edificação } \\
\text { considerada patrimônio, onde funcionou o hospital } \\
\text { da cidade }\end{array}$ \\
\hline Rio Grande & $\begin{array}{l}\text { Bibliotheca Riograndense } \\
\text { Fundada em } 1846 . \\
\text { É a única biblioteca a possuir a coleção } \\
\text { completa do jornal local, o Diário do Rio } \\
\text { Grande }\end{array}$ & $\begin{array}{l}\text { A biblioteca mudou-se para seu atual prédio no ano } \\
\text { de } 1902 \text {, já com } 56 \text { anos de existência. É a mais } \\
\text { antiga instituição de cultura do Rio Grande do Sul. } \\
\text { Foi sede da Casa da Câmara, com estilo Neoclássico }\end{array}$ \\
\hline Rio Grande & $\begin{array}{l}\text { Biblioteca Pública } \\
\text { Infantil Monteiro Lobato }\end{array}$ & Situada junto à Bibliotheca Riograndense \\
\hline $\begin{array}{l}\text { Santo Antônio da } \\
\text { Patrulha }\end{array}$ & Bib. Pub. Mun. Júlio Costa & $\begin{array}{l}\text { Biblioteca está estabelecida em um prédio } \\
\text { construído em } 1865 \text { para residência particular. Em }\end{array}$ \\
\hline
\end{tabular}




\begin{tabular}{|c|c|c|}
\hline & $\begin{array}{l}\text { Fundada em } 4 \text { de agosto de 1958, com abertura } \\
\text { em 1993. Com acervo diversificado e espaço } \\
\text { para infantil. }\end{array}$ & $\begin{array}{l}1920 \text { foi adquirido para funcionamento da } \\
\text { intendência do município. O prédio foi tombado } \\
\text { pelo Patrimônio Histórico de Santo Antônio da } \\
\text { Patrulha pela Lei } 2.491 / 92 \text {, no ano de } 1992 \text {, e pelo } \\
\text { IPHAE, em 2012. }\end{array}$ \\
\hline $\begin{array}{l}\text { São Lourenço do } \\
\text { Sul }\end{array}$ & $\begin{array}{l}\text { Bib. Púb. Mun. Mal. Humberto de Alencar } \\
\text { Castelo Branco } \\
\text { Fundada em } 1942\end{array}$ & $\begin{array}{l}\text { Edificação projetada pelo engenheiro alemão } \\
\text { Carlos Othon Knüpplen, em 1919. Em estilo } \\
\text { neoclássico, recebeu de seu construtor o nome de } \\
\text { Solar Bella Vista em virtude de sua vista da cidade } \\
\text { e de parte da Lagoa dos Patos. Ao longo dos anos, o } \\
\text { prédio abrigou a Intendência Municipal, a delegacia } \\
\text { de Polícia, a Cadeia Pública e um hospital a cargo } \\
\text { do médico Gustav Holl. O prédio abriga a } \\
\text { Biblioteca, o Museu, a Coordenadoria de Cultura e } \\
\text { o Arquivo Histórico. }\end{array}$ \\
\hline Sobradinho & Bib. Pub. Mun. Felícia Almeida Forzen Vidal & $\begin{array}{l}\text { A edificação é de } 1932 \text {, com estilo renascentista } \\
\text { italiano. A biblioteca funciona no local desde } 2012 \text {, } \\
\text { junto ao Museu Municipal, Arquivo Histórico e o } \\
\text { Espaço Vêneto. Foi tombada como Patrimônio } \\
\text { Histórico Municipal pela Lei no } \mathrm{n}^{\circ} 916 / 84 \text { de } \\
\text { 12/11/1984. Inaugurada em 03/12/1987, como Casa } \\
\text { da Cultura Amário João Lazzari, tendo como } \\
\text { primeiro diretor o Professor Jary Schirmer. }\end{array}$ \\
\hline Tupanciretã & Bib. Pub. Mun. Doutor Pedro Pinto & $\begin{array}{l}\text { A resposta foi que o prédio tem valor cultural para a } \\
\text { cidade. }\end{array}$ \\
\hline Vale Real & Bib. Pub. Mun. Padre Benno Petry & $\begin{array}{l}\text { A unidade está instalada na Casa da Cultura, onde } \\
\text { funciona também o Museu da Colonização e o } \\
\text { Telecentro. Considerado local histórico, sendo } \\
\text { antiga residência (em estilo enxaimel) de um } \\
\text { professor residente no município no século passado. } \\
\text { Além disso, o entorno deste ambiente contempla a } \\
\text { Casa do Artesão (no mesmo estilo arquitetônico) e } \\
\text { o Centro de Convivência Arno Stoffels. }\end{array}$ \\
\hline
\end{tabular}

Fonte: Dados da pesquisa, obtidos por resposta aos e-mails e pesquisa.

Dentre estas 27 bibliotecas públicas, foram escolhidas três como sujeitos da pesquisa, segundo critério de facilidade de acesso para as pesquisadoras.

A próxima seção traz a análise das entrevistas realizadas com as responsáveis pelas três unidades eleitas: a Biblioteca Pública Municipal Machado de Assis, em Novo Hamburgo, com entrevista com a bibliotecária Maria Denise Mazzali Konarzewski; a Biblioteca Pública Municipal Júlio Costa, em Santo Antônio da Patrulha, com Bianca Teixeira Ramos, e a Biblioteca Pública do Estado do Rio Grande do Sul, em Porto Alegre, com Morgana Marcon.

\section{ANÁLISE DAS ENTREVISTAS}

A primeira pergunta somente confirmava se a unidade funciona em um patrimônio cultural edificado. Na segunda, solicitou-se que os bibliotecários contassem sobre a edificação e foi declarado que não havia um domínio das informações referentes à edificação da unidade por duas bibliotecárias. No entanto, uma das bibliotecárias que disse não dominar as 
informações, sabe contá-las de forma afetiva e interessada. Além disso, mantém apontamentos sobre a edificação e a unidade, os quais busca manter atualizados. Neles, descreve a trajetória da biblioteca, nomes dos fundadores, ex-bibliotecários, ações culturais e informações sobre a edificação desde sua construção, além de pessoas que moraram no local e instituições que já tiveram suas sedes instaladas no casarão. A terceira bibliotecária, ao ser solicitada a contar sobre a edificação, mostrou que domina as informações sobre a sua unidade, a ponto de trazer diversos detalhes e contá-los com entusiasmo, sabendo datas, nomes e fatos centenários, evidenciados na sua narrativa.

Diante das três respostas sobre a edificação considerou-se que existe a valorização do patrimônio cultural por duas entrevistadas. Essa afirmativa é depreendida pelo conhecimento expresso no relato, tanto no que trazia de informações precisas e detalhadas como pela forma como foi contada, envolvendo entusiasmo e revelando uma relação de afeto com o objeto.

A terceira pergunta - "Como você percebe o fato da unidade funcionar em um patrimônio cultural?" - trouxe relatos que apontam para as dificuldades de uma biblioteca funcionar em um patrimônio cultural edificado. As respostas são diferentes e é interessante apresentar trechos para reflexão. Duas entrevistadas revelam a necessidade de a biblioteca funcionar em outro local ou ter um anexo. Uma das entrevistadas afirmou:

\footnotetext{
Acho o prédio muito bonito, mas talvez ele tivesse que ser aproveitado para outro função ou atividade cultural, e não para biblioteca. Primeiro porque não podemos mais expandir o prédio. Não podemos fazer reforma. Não na fachada que é muito bonita. Mas ao longo dos anos a biblioteca cresceu muito e nós não temos mais para onde expandir. Não há espaço, ambientes adequados, para cada atividade que se deseja fazer. Estamos engessados e sufocados. Apensar de ser um prédio bonito de se trabalhar, com uma boa ventilação, bem iluminado. Mas, seguido estamos com problema de parede úmida, goteiras. E quando é preciso reformar, cada vez é um transtorno. È preciso fechar a biblioteca, tirar muito material do lugar. Isso acaba deteriorando o próprio acervo de tanta mudança. Algumas vezes chegamos aqui e descobrimos goteiras em cima dos livros. Se tivesse que escolher, iria preferir fazer um prédio planejado para a biblioteca pública. (Entrevistada A).
}

Outra das três bibliotecárias foi taxativa ao dizer que o prédio não atende mais às necessidades de uma biblioteca. Detalhou as várias tentativas que fez junto ao governo para conseguir um anexo e transformar a unidade tombada em uma biblioteca-museu, com espaço para exposições, lançamentos de livros, saraus e recitais, ou seja, ações culturais. O anexo que seria na área central, com salas para oficina, música, informação, informática e acervo não foi conseguido, segundo ela, por questões políticas e orçamentárias.

A terceira entrevistada respondeu que é “[...] válido e importante que a biblioteca funcione em um patrimônio cultural edificado porque há um resgate da história local”. Menciona que quando as pessoas viajam sempre visitam centros históricos e culturais, 
estabelecidos em patrimônios edificados. No entanto, as dificuldades também foram apontadas em sua fala:

Enfrentamos dificuldades, como a umidade em parte das paredes. Na fachada não podemos mexer em nada. Por causa da estrutura das janelas, entra água pela frente. Já se pensou em colocar toldos, mas isso é inviável. Ar condicionado também não pode em alguns lugares, somente em uma determinada parede. No verão é muito quente. O que ajuda é a parede um metro de largura. As janelas são pesadas para abrir. (Entrevistada C).

A pergunta acerca da percepção do funcionamento da unidade em uma edificação considerada patrimônio cultural desencadeou a apresentação de uma série de dificuldades enfrentadas pelas bibliotecárias com os prédios tombados, como problemas de infraestrutura e preservação. Pode-se avaliar que a valorização está diretamente relacionada com as tensões e dificuldades enfrentadas na manutenção do patrimônio. Se a edificação traz problemas e preocupações constantes, a sua valoração decai. Mas percebeu-se que talvez o problema não esteja na edificação em si, mas na falta de verba para manter as unidades, preservá-las e sanar rapidamente os problemas. Além de investimento que proporcione um anexo, como sugerido no caso das unidades de Porto Alegre e Novo Hamburgo.

A quarta questão - "Como o bibliotecário percebe a relação do usuário com o patrimônio?" - buscou a visão subjetiva do bibliotecário sobre essa relação, sem se preocupar com quantificação. As três respostas enunciam em alguns momentos um encantamento, uma admiração e interesse pelo patrimônio. Uma das bibliotecárias lembrou que foi a comunidade que não deixou o prédio ser demolido e mencionou que os usuários ficam admirados com o descaso com a manutenção do edifício por parte da Prefeitura. Resposta semelhante é dada por outra entrevistada: ao mesmo tempo em que destaca a admiração e encantamento do público pela edificação, também menciona que a unidade está muito aquém do que se esperaria desse tipo de espaço, citando as bibliotecas públicas do Acre e de Fortaleza como unidades fantásticas no que se refere ao espaço que oferecem.

As perguntas cinco e seis questionavam se os funcionários são estimulados a conhecer a história do patrimônio edificado. A entrevistada A informou que todos eles sabem que é um prédio histórico, mas que no momento há uma troca de funcionários, então eles irão conhecer aos poucos a história. Acrescentou: "[...] até porque dentro de uma biblioteca há muitas outras atividades para aprender e tomar conhecimento". A segunda entrevistada informou que divide, atualmente, suas tarefas somente com outra funcionária, sendo que ambas realizam visitas guiadas e falam sobre a edificação. A terceira entrevistada foi a mais enfática ao afirmar que 
todos os funcionários conhecem a história do prédio: " Chegam a contar histórias, pois já estão há muito tempo trabalhando por aqui."

As perguntas de 7 a 12 - que envolviam questões sobre materiais impressos de divulgação (folhetos, flyers ou catálogos) e divulgação nos ambientes virtuais (site oficial, blogs e redes sociais) - trazem respostas semelhantes. As três bibliotecas não possuem material próprio impresso por falta de dinheiro e não possuem site no momento. No entanto, as entrevistadas acreditam que essas seriam boas formas de divulgar a instituição e sua edificação.

Uma das bibliotecas possui poucos documentos, livros e registros sobre a edificação há somente uma cópia xerox de um texto de um historiador sobre o imóvel e um recorte de jornal. O material que a unidade detinha foi repassado para o arquivo da cidade, órgão que, segundo a bibliotecária, possui melhor estrutura que a biblioteca para acondicionar e preservar documentos históricos. Ela lembrou que é feita, não de forma constante, uma coleta de informações sobre o patrimônio quando alguém aparece falando sobre suas memórias pessoais relacionadas com a casa. Quem faz a coleta de depoimentos é um historiador da Secretaria de Cultura do município.

A segunda biblioteca não tem material impresso sobre a unidade. Sua imagem aparece identificada em folders de turismo da Prefeitura da cidade. Mas há dois livros escritos por uma historiadora local que tratam da história da cidade e da influência luso-açoriana na colonização. Neles a edificação da biblioteca aparece entre os patrimônios culturais. A BPE/RS também não tem material impresso sobre o patrimônio edificado, mas em seu acervo podem ser consultados documentos que tratam do tema.

Sobre o uso de ambientes virtuais (site oficial, blogs e redes sociais) para divulgar o patrimônio, as duas unidades municipais enfrentam a mesma restrição por suas Secretarias de Cultura. Ambas não estão autorizadas a fazer uso de quaisquer mídias. Se desejarem alguma divulgação no site ou no Facebook da sua Prefeitura precisam enviar material para ser avaliado e autorizado pela respectivas secretarias de cultura.

O que há no Facebook, em uma busca feita pela pesquisadora, no que se refere a uma das bibliotecas, são publicações que aparecem em decorrência das pessoas executarem a ferramenta check-in, oferecida pela rede social. Ou seja, nem a Biblioteca e nem a Secretaria de Cultura têm gerência sobre o que vai sendo publicado - como visitações feitas à unidade, registros de lançamento de livros e alunos que passam no local para estudar. Pode-se inferir que a Biblioteca, por falta dessa autorização da Secretaria de Cultura, está perdendo a chance de divulgar suas atividades, e que há interesse das pessoas de publicarem que estão 
frequentando ou visitando a unidade. O que há no site da Secretaria da Cultura é uma menção, em destaque, com foto ampla da Biblioteca e sua edificação, informando sobre o seu tombamento.

A terceira biblioteca está com um site desatualizado - pois ainda menciona o setor de empréstimos funcionando em outro prédio, local onde esteve instalada durante o último restauro do prédio -, e não há previsão para sua atualização, o que a pesquisadora considera um prejuízo para quem faz pesquisas ou busca informações sobre a unidade. Esta biblioteca tem página do Facebook com uma imagem de destaque de um salão bastante enaltecido. Ao longo de 2017, foram contabilizadas três publicações específicas sobre o patrimônio: no dia 3 de fevereiro (para anunciar os serviços da unidade e seus horários durante o mês e com um chamado para conhecer o patrimônio) foram postadas nove fotos, dentre elas da fachada, das salas e ornamentos; no dia 25 de abril, por ocasião do Dia Internacional do Livro, celebrado dia 23 de abril, foi postado um link com a gravação de uma entrevista da diretora da biblioteca em uma importante rádio local, na qual foi falado sobre a biblioteca, serviços e patrimônio edificado; no mês de setembro, nos dias 2 e 3, foi feita divulgação de uma atividade musical para marcar o aniversário da inauguração do prédio, no dia 7 de setembro de 1922. Nos comentários da página, há diversas avaliações com elogios ao patrimônio edificado, ressaltando sua beleza. A unidade faz, em média, pelo menos quatro postagens na semana para divulgar suas atividades culturais mas esse número pode variar para mais ou menos, de acordo com as ações da biblioteca.

Tendo em vista as observações realizadas, pode-se afirmar que os ambientes virtuais das bibliotecas estão sendo pouco aproveitados. A falta de autorização para o uso independente de mídias sociais gratuitas por parte das bibliotecárias parece uma imposição arbitrária. A biblioteca que tem autonomia e possibilidade de livre uso, não aproveita a mídia social Facebook para divulgar o patrimônio edificado, o que poderia informar seus usuários e atrair a curiosidade para ser feita uma visita ao local.

As questões de 13 a 19 fizerem referência às atividades culturais que buscam valorizar o patrimônio cultural edificado. As respostas das três entrevistadas foram semelhantes, informando que no momento somente a visita guiada, que precisa ser previamente agendada, é a atividade que promove a divulgação da edificação. Sobre a possível implementação de alguma ação, uma das bibliotecárias apontou somente dois projetos, sendo que ambos vieram de pessoas e instituições de fora da biblioteca: o primeiro é o de um historiador que deseja fazer um vídeo sobre o prédio para ser exibido quando forem realizadas visitações guiadas; a outra 
proposta a ser realizada é por uma turma do curso de Marketing de uma universidade local, que deseja incluir a biblioteca nas visitações turísticas da cidade, por causa da edificação.

$\mathrm{Na}$ maior das três bibliotecas também, no momento, somente a visita guiada é a atividade que faz essa recuperação histórica do patrimônio edificado. Tentou-se agendar a visitação guiada, mas esta não é oferecida na forma individual, somente para grupos. Ao tentar ser incluída em um grupo houve dificuldades, pois se o grupo tem mais de 20 pessoas não é aceita a inclusão. Geralmente as visitas são agendadas por escolas da Capital ou do Interior.

A pergunta 18 foi sobre se alguma vez tinha sido feita uma exposição sobre a narrativa do patrimônio. Uma das entrevistadas disse que somente uma vez foi feita uma mostra sobre a edificação e sua trajetória na Feira do Livro da cidade. As fotografias usadas foram obtidas em um museu da cidade. Outra das entrevistadas afirmou que a biblioteca promoveu duas exposições, sendo a última em parceria com o Museu de Arte do Rio Grande do Sul, nos 140 anos da biblioteca. Realmente as três bibliotecas não estão envolvidas em divulgação sistemática, pelo menos uma ou duas vezes ao ano, do patrimônio edificado. Somente uma das três marcou uma data importante, seja para a unidade ou para o município ou unidade da federação.

As últimas perguntas, de 20 a 22, foram sobre orçamento para a preservação da edificação e se alguma vez a funcionária recebeu orientação sobre a preservação do patrimônio. Uma das entrevistadas disse que nunca recebeu orientação sobre o que se pode fazer ou não em uma edificação tombada. Confessou que se sente parcialmente responsável pelo prédio, pois sempre que há um problema é ela quem faz a notificação e solicita a visita de um especialista da Secretaria da Cultura para averiguar a situação, seja arquiteto ou engenheiro da Prefeitura. A segunda entrevistada, da mesma forma, nunca recebeu orientação, mesmo tendo o Conselho de Patrimônio ocupado a biblioteca para suas reuniões por um período. O que sabe também buscou por conta própria e sempre questiona o Conselho ou a Secretaria sobre o que pode ser feito ou não na unidade. A terceira entrevistada recebeu informações dos profissionais que trabalharam no restauro da biblioteca, mas também buscou se informar sobre preservação e patrimônio tombado por seu próprio interesse. Todas buscam sanar o mais rápido possível os problemas relacionados com a preservação da edificação, mas sempre encontram dificuldades para a administração pública liberar verba, algo demorado e que envolve processos burocráticos.

Sobre orçamento e verbas todas enfrentam dificuldades. Com um orçamento muito restrito para suas demandas, as bibliotecas precisam limitar suas ações, atividades e gastos com 
material. A terceira entrevistada relata que não existe orçamento para a biblioteca, o que existe é um orçamento geral da Secretaria de Cultura do Estado, de forma que sempre que há necessidade é feito solicitação para a secretaria. A biblioteca pela qual é responsável conta com ajuda financeira oriunda de uma Associação de Amigos da Biblioteca; por meio da associação a unidade faz locações para gravações de filme, propaganda, entre outros. Com esse dinheiro arrecadado é feita a manutenção - como o conserto de uma hidra do banheiro - e compra de ventiladores e computadores.

A primeira entrevistada conta que a parte orçamentária destinada à biblioteca é para manutenção, que abrange tudo o que é preciso para a unidade. O valor é pequeno, em torno de $\mathrm{R} \$ 5000,00$ (cinco mil reais) no ano, e deve ser usado para objetos, materiais e atividades. A entrevistada dois também comentou que a mesma situação de falta de verba ocorre em sua cidade, mas adiantou que no próximo ano será feito um restauro, que está em torno de $\mathrm{R} \$$ 250.000,00 (duzentos e cinquenta mil reais), para consertar telhado, janelas e partes do piso.

A observação do espaço físico sobre a existência de menção sobre o patrimônio edificado proporcionou algumas observações. Na primeira biblioteca, a única referência sobre a história da edificação é uma placa na entrada. Na segunda há somente uma placa em homenagem à figura que dá nome à unidade, e em um balcão estão dispostas informações turísticas da cidade, nas quais a biblioteca aparece como referência de edificação com influência portuguesa.

Como se pode perceber, a observação do espaço físico mostrou que muito pouco é realizado pelas bibliotecas públicas para divulgar o patrimônio em suas dependências. Acredita-se que a ação de divulgar o patrimônio edificado no espaço físico é importante, principalmente no caso de instituições que, como mencionado, dispõem de poucos recursos financeiros. Assim, em tempos de parcos investimentos em cultura, sobretudo nas bibliotecas, medidas como essas podem ser uma boa alternativa. Somente um cartaz ou um mural com fotos, acompanhadas de informações, já seria uma forma de divulgar a edificação.

\section{CONSIDERAÇÕES FINAIS}

Com base nos dados coletados pode-se perceber que em uma escala que inclui "totalmente", "parcialmente" e "não valoriza", o bibliotecário valoriza parcialmente o patrimônio cultural edificado onde sua unidade está estabelecida. Essa afirmativa parte do relato das três bibliotecárias entrevistadas, pois, ao ser solicitado que elas falassem livremente 
sobre o patrimônio edificado, problemas e dificuldades foram apontados em detrimento das qualidades, o que denota que existe o reconhecimento da importância da edificação, mas os problemas se sobrepõem à valoração. As dificuldades apontadas - como a manutenção da edificação, a falta de espaço para abrigar um acervo que aumenta (a biblioteca, um organismo em crescimento) e a "falta de verba" (a eterna escassez de recursos) para sanar as demandas da instituição - parecem desgastar a relação do bibliotecário com a Administração Pública estadual ou municipal, mantenedora do bem cultural. Somado a isto, a única atividade cultural promovida pelas bibliotecárias voltada a divulgar o patrimônio edificado é a visita guiada, além da pouca divulgação do patrimônio, seja em ambientes virtuais ou físicos das unidades.

As bibliotecárias demonstram preocupação em sanar os problemas de manutenção e preservação da edificação de forma rápida, mas sempre esbarram no problema da política de gestão governamental quem impõe processos burocráticos demorados e exaustivos para comprovar a importância da demanda e para aprovar a liberação do montante solicitado. $\mathrm{O}$ Estado não apenas deveria investir muito mais em cultura, mas também destinar uma verba específica com a finalidade da manutenção do patrimônio, além de autorizar e propiciar que cada unidade tenha seu site ou blog, ou pelo menos uma conta em uma mídia social, geralmente gratuita. As publicações poderiam auxiliar na divulgação da biblioteca, fazendo com que a unidade esteja presente e seja lembrada pela comunidade da qual faz parte.

A falta de iniciativas para a realização de ações voltadas ao patrimônio histórico é visível. Mesmo com a carência de recursos provenientes do Governo, poderiam ser tentadas alternativas. Como exemplo de ação cultural conscientizadora da população poderia ser promovida uma palestra voluntária de um bibliotecário, arquiteto ou especialista em patrimônio para abordar a edificação e sua memória, sem custos monetários, mas que poderia gerar capital simbólico de reconhecimento e envolvimento da comunidade. Outro exemplo de ação a ser empreendida poderia ser a criação de uma associação de amigos, sem fins lucrativos, constituída por membros da comunidade que decidam voluntariamente unir seus esforços para apoiar a biblioteca no seu trabalho diário, visando à otimização dos serviços prestados. A associação de amigos se mostrou de grande valor para uma das unidades pesquisadas, pode se tornar um canal de comunicação e integração entre comunidade e o governo, promovendo um clima favorável em relação à biblioteca.

A pesquisa forneceu um diagnóstico da situação atual de três bibliotecas públicas do Rio Grande do Sul, que, ao que tudo indica, deve ser muito semelhante a vivida por outros unidades com o mesmo cenário, principalmente no que se refere ao espaço físico. Também, a 
partir do referencial teórico refletiu-se sobre o conceito de patrimônio, sua valorização simbólica e sua capacidade de sedimentar a memória e a identidade de uma coletividade em "pedra e cal". Espera-se que os pesquisadores da Ciência da Informação e os bibliotecários voltem sua atenção para os temas desenvolvidos neste trabalho, que são alvos de um número reduzido de estudos, principalmente se observarmos que muitas são as unidades estabelecidas em patrimônios edificados em nível estadual. Uma reflexão sobre o assunto poderia trazer alternativas sobre como os bibliotecários podem conseguir transformar a sua condição financeira precária, como implementar projetos para divulgar o patrimônio cultural, como tirar proveito dessa situação e ter outra percepção sobre o patrimônio edificado.

Aliás, este foi um resultado parcial não esperado, o número de prédios considerados históricos não foi tão pequeno: 27 bibliotecas públicas responderam que estão estabelecidas em edificações consideradas patrimônio cultural, dentro do universo das 144 que se pronunciaram sobre a pergunta enviada - sendo o total atualmente de 534 bibliotecas públicas cadastradas no Sistema Estadual de Bibliotecas Públicas do Rio Grande do Sul.

É importante lembrar que, conforme mencionado, as bibliotecas públicas têm a função de oferecer acesso ao lazer, à cultura, à educação e à informação de forma gratuita. Ao mesmo tempo também são lugares de memória enquanto espaços físicos - edifícios construídos com a finalidade de armazenar acervos, repositórios da memória em si, com a incumbência de guarda de informação e conhecimento. Diferente de outras bibliotecas, que estão em locais sem nenhuma referência de memória e sem nenhum valor histórico, as que estão estabelecidas em um patrimônio cultural edificado deveriam explorar esse diferencial, visto que isso não é sinônimo de "antiquado" (ou até mesmo "velho" e sem inovações), pois muitas instituições em outros países oferecem o que há de mais moderno, em tecnologia e serviço, em edificações históricas e tombadas. Muito provavelmente se houvesse verba disponível para a manutenção e preservação do patrimônio ou a criação de um anexo, como foi mencionado por duas entrevistadas, com certeza seria outra a percepção sobre o bem cultural.

Percebe-se, por fim, contradições interessantes na questão de atribuição de valor, pois essa outorga ao bem material somente se torna visível e se consubstancia quando são investidos valores reais (numerário) para manutenção deste bem cultural. Caso contrário se torna uma edificação (espaço) onde os problemas suplantam as qualidades. A outra verificação é que muitas bibliotecas públicas são alocadas em prédios históricos com a intenção de conferir e ampliar a aura de erudição e outras tiveram seus prédios construídos em pontos centrais da cidade, dividindo espaço com símbolos de poder - como palácios de governos e da justiça, 
sedes de prefeituras e câmara de vereadores -, evidenciando sua relevância no imaginário coletivo. Mesmo com essa distinção, as bibliotecas públicas não recebem a valoração por parte de seu mantenedor, pois muitas passam dificuldades em relação a aspectos de recursos humanos, no cumprimento de suas funções e na sua infraestrutura.

\section{REFERÊNCIAS}

ARARIPE, Fátima M. Alencar. Do patrimônio cultural e seus significados.

Transinformação, Campinas, v. 16, n. 2, p. 111-122, maio/ago. 2004. Disponível em: $<$ http://revistas.puc-campinas.edu.br/transinfo/viewarticle.php?id=63>. Acesso em: 14 ago. 2017.

BIBLIOTECA PÚBLICA DO RIO GRANDE DO SUL. Histórico da biblioteca. 2017. Disponível em: <http://www.bibliotecapublica.rs.gov.br/>. Acesso em: 27 out. 2017.

BOURDIEU, Pierre. O poder simbólico. Rio de Janeiro: Bertrand Brasil, 1989.

CHOAY, Françoise. Alegoria do patrimônio. Lisboa: Edições 70, 2006.

GERHARDT, Tatiana Engel; SILVEIRA, Denise Tolfo (Org.). Métodos de pesquisa. Porto Alegre: Ed. UFRGS, 2009. Disponível em:

<ww.ufrgs.br/cursopgdr/downloadsSerie/derad005.pdf>. Acesso em: 29 mar. 2017.

GIL, Antonio Carlos. Como elaborar projetos de pesquisa. 4. ed. São Paulo: Atlas, 2002.

GONÇALVES, José Reginaldo Santos. Antropologia dos objetos: museus e patrimônios. Coleção Museu, Memória e Cidadania: Rio de Janeiro, 2007

HALBWACHS, Maurice. A memória coletiva. São Paulo: Centauro, 2006.

KONARZEWSKI, Maria Denise Mazzali. Entrevista concedida a Luciana Prestes Vicente. Porto Alegre, 16 out. 2017. 1 arquivo (60 min).

LE GOFF, Jacques. História e memória. Lisboa: Edições 70, 1982. 
MACHADO, Gina Gomes. A sociedade civil e a preservação do patrimônio. In:

CARVALHO, Claudia S.; GRANATO, Rafael Z.; e BENHETRIT, Sarah F. Um olhar contemporâneo sobre a preservação do patrimônio cultural material. Rio de Janeiro: Museu Histórico Nacional, 2008. p. 276 - 284.

MARCON, Morgana. Entrevista concedida a Luciana Prestes Vicente. Porto Alegre, 08 out. 2017. 1 arquivo (90 $\mathrm{min})$.

NORA, Pierre. Entre memória e história: a problemática dos lugares. n.10. Projeto História: São Paulo, 1993.

PESAVENTO, Sandra Jatahy. História, memória e centralidade urbana. Revista Mosaico, Goiás, v. 1, n. 1, p. 3-12, jan./jun. 2008. Disponível em:

<http://seer.pucgoias.edu.br/index.php/mosaico/article/view/225>. Acesso em: 03 out. 2017.

POULOT, Dominique. Um ecossistema do patrimônio. In: CARVALHO, Claudia S.; GRANATO, Rafael Z.; BENCHETRIT, Sarah F. Um olhar contemporâneo sobre a preservação do patrimônio cultural material. Rio de Janeiro: Museu Histórico Nacional, 2008. p. $26-43$.

RAMOS, Bianca Teixeira. Entrevista concedida a Luciana Prestes Vicente. Porto Alegre, 18 out. 2017. 1 arquivo (80 $\mathrm{min})$.

RICOEUR, Paul. A memória, a história, o esquecimento. São Paulo: Editora Unicamp, 2007.

SISTEMA ESTADUAL DE BIBLIOTECAS PÚBLICAS DO RIO GRANDE DO

SUL. Lista de Bibliotecas do RS. Disponível em: <http://sebprs.blogspot.com.br/p/lista-debibliotecas-do-rs.html>. Acesso em: 01 set. 2017.

SISTEMA NACIONAL DE BIBLIOTECAS PÚBLICAS. Sistemas estaduais. Disponível em: <http://snbp.culturadigital.br/historico/>. Acesso em: 27 out. 2017.

YÁÑES, Célia Martinez. El patrimonio cultural: los nuevos valores, tipos, finalidades y formas de organización. Granada: Editorial de la Universidad de Granada, 2006. 1461 p. 